\title{
Enhanced adhesion buffer layer for deep x-ray lithography using hard $\mathrm{x}$-rays
}

Francesco De Carlo, Joshua J. Song, Derrick C. Mancini

Advanced Photon Source APS-XFD, Argonne national Laboratory

1

Experimental Facilities Division

Advanced Photon Source, Argonne National Laboratory

Argonne, IL 60439

RECEIVEC
SEP 211999
OS T I

\begin{abstract}
The submitted manuscript has been created by
the University of Chicago as Operator of

Argonne National Laboratory ("Argonne") under

Contract No. W-31-109-ENG-38 with the U.S.

Deparment of Energy. The U.S. Government

retains for itself, and others acting on its behalf,

a paid-up, nonexclusive, irrevocable worldwide

license in said article to reproduce, prepare

derivative works, distribute copies to the public,

and perform publicly and display publicly, by

or on behalf of the Government.
\end{abstract}

\footnotetext{
*This work is supported by the U.S. Department of Energy, Basic Energy Sciences-Materials Sciences, under contract \#W-31-109-ENG-38.
} 


\section{DISCLAIMER}

This report was prepared as an account of work sponsored by an agency of the United States Government. Neither the United States Government nor any agency thereof, nor any of their employees, make any warranty, express or implied, or assumes any legal liability or responsibility for the accuracy, completeness, or usefulness of any information, apparatus, product, or process disclosed, or represents that its use would not infringe privately owned rights. Reference herein to any specific commercial product, process, or service by trade name, trademark, manufacturer, or otherwise does not necessarily constitute or imply its endorsement, recommendation, or favoring by the United States Government or any agency thereof. The views and opinions of authors expressed herein do not necessarily state or reflect those of the United States Government or any agency thereof. 


\section{DISCLAIMER}

Portions of this document may be illegible in electronic image products. Images are produced from the best available original document. 


\title{
Enhanced adhesion buffer layer for deep x-ray lithography using hard x-rays
}

\author{
Francesco De Carlo, Joshua J. Song, Derrick C. Mancini \\ Advanced Photon Source APS-XFD, Argonne National Laboratory, \\ 9700 S. Cass Ave., Argonne, IL 60439
}

\section{Abstract}

The first step in the fabrication of microstructures using deep x-ray lithography (DXRL) is the irradiation of a x-ray sensitive resist like polymethylmethacrylate (PMMA) by hard x-rays. At the Advanced Photon Source, a dedicated beamline allows the proper exposure of very thick (several $\mathrm{mm}$ ) resists. To fabricate electroformed metal microstructures with heights of several mm, a PMMA sheet is glued onto a metallic plating base. An important requirement is that the PMMA layer must adhere well to the plating base. The adhesion is greatly reduced by the penetration of even a small fraction of hard $\mathrm{x}-$ rays through the mask absorber into the substrate. In this work we will show a novel technique to improve the adhesion of PMMA onto high-Z substrates for DXRL. Results of the improved adhesion are shown for different exposure/substrate conditions.

\section{Introduction}

In the LIGA process [1], used for the fabrication of electroformed microstructures, the first step is deep x-ray lithography (DXRL). DXRL consists of exposing a thick resist, which has been coated onto a substrate, to $\mathrm{x}$-rays through a $\mathrm{x}$-ray mask. At the Advanced Photon Source (APS), the deep x-ray exposure is performed at beamline 2BM [2] using thick (> $1 \mathrm{~mm}$ ) polymethylmethacrylate (PMMA) resists. After the exposure the resist is 
developed and used as a template for electroforming various metals. Finally the resist is stripped off, leaving the desired metallic structures, Figure 1.

One of the most important requirements of this technique is good adhesion of the PMMA layer to the plating base[3], [4], [5]. As described by Pantenburg et al. [6], the adhesion can be greatly reduced by electrons and fluorescence photons that are created during the irradiation beneath the mask absorber. X-ray absorption by the metallic plating base results in substrate-generated photoelectrons being absorbed in the resist near the substrate. The exposure of the resist by these additional photoelectrons from the substrate makes the PMMA near the interface soluble in the developer and thus contributes to loss of adhesion.

High energy photons are desirable for DXRL due to their greater penetration and therefore their ability to uniformly expose very thick resist layers (up to several $\mathrm{mm}$ ). In Figure 2, the transmitted $x$-ray intensity versus energy during PMMA exposures for DXRL at the APS is shown. Loss of adhesion may become especially pronounced when using these very high energy photons, because of the increased range of the substrate- generated photoelectrons and their higher intensity.

A 1-mm PMMA sheet was patterned by exposure at the APS with a $0.15^{\circ} \mathrm{Pt}$-mirror and a 1-mm C-filter followed by GG development [7], [8]. This sample was prepared by gluing PMMA on a Si wafer coated with $\mathrm{Cr} / \mathrm{Au}$ using a standard gluing process [9]. The resulting structures (Figure 3) show a significant loss of adhesion.

A common solution to the problem of poor adhesion is to increase the gold absorber thickness of the mask or to replace the plating base with a lower density metal. An increase in the gold absorber thickness is not always possible or desirable mainly because of the high stress of the electroplated gold and difficulties to plate uniformly over $100 \mu \mathrm{m}$ or more. Also the choice of substrate/plating base is often determined by constraints other than the desire for low $\mathrm{x}$-ray absorption. 
Our approach does not seek to reduce the secondary electron emission from the plating base but rather to improve adhesion by moving the resist away from the substrate where the photoelectrons are generated. This is achieved using an inert low- $\mathrm{Z}$ organic material as a buffer layer with a thickness of the order of the penetration length of the photoelectrons, in our case $\sim 3 \mu \mathrm{m}$. The thickness of this layer is set to be just greater than the range of energy dissipation of substrate-generated photoelectrons.

In order to move the resist away from the region where the electrons are generated, the standard LIGA process has been consequently modified as shown in Figure 4 . In the substrate preparation, we spin-coat a buffer layer. A polyimide film such as the Dupont Pyralin $\circledast$ resin PI2545, has been used as a buffer layer as it meets the requirements; other radiation-resistant polymers may also be used. The adhesion between the polyimide layer and the PMMA can be further enhanced by roughening the polyimide with a short $\mathrm{RIE} /$ plasma etching step.

The photoelectrons generated in the substrate will be absorbed in this buffer layer and dissipated without damaging the resist. After developing the resist, the buffer layer is removed by anisotropic etching using oxygen $\mathrm{RIE}$ with negligible harm to the resist layer. Thereafter, the patterned resist layer can be plated as usual and the resist stripped with solvent. After the stripping, additional RIE is required to remove the remaining buffer layer.

Optimization of the buffer layer has also been investigated. This is necessary because it is very important to achieve negligible damage to the resist layer during the anisotropic etching step. Different buffer layers have been tested with the objective of minimizing the oxygen plasma power/time. Polyimide gives the best results in terms of adhesion, but to remove it requires more then $2 \mathrm{~h}$ at $100 \mathrm{~W}$ of oxygen plasma, which damages the PMMA structures. The use of materials that are easy to remove (like $\mathrm{AZ}$ resist) has disadvantages primarily due to the fact that the stress of a thick $\mathrm{AZ}$ resist is high, and it 
is damaged by the secondary electron emission from the plating base. The best solution has been a suitable combination of these two materials, i.e., we first spin a thin layer of polyimide, $\sim 0.5-1 \mu \mathrm{m}$, directly on the substrate, and then to reach the required thickness we spin a second layer of $A Z 1828$ resist. In this way, by keeping the $A Z$ far from the interface, we greatly reduce its radiation damage and we keep the polyimide thin enough to be removed easily.

\section{Results and Discussion}

The use of an optimized buffer layer has improved the adhesion under different DXRL exposure/substrate conditions. In particular, we have used a resolution mask, consisting of a $300-\mu \mathrm{m}$ Si membrane and $\sim 70-\mu \mathrm{m}$ thick Au absorbers, to expose different substrates; with the same beamline configuration, substrates were prepared having 15,30 , and $45 \mathrm{~nm} \mathrm{Au}$ as a plating base and 1-mm glued or $150-\mu \mathrm{m}$ spin-coated PMMA. All substrates were prepared with the optimized buffer layer. No differences were observed among the different $\mathrm{Au}$ plating base substrates of various thicknesses. In Figure 5, the smallest $(2 \mu \mathrm{m})$ attached structures are shown for a resolution mask exposure onto a $\sim 1$ mm PMMA glued substrate. The aspect ratio is this case is $\sim 475$. In Figure $6,100 \mu \mathrm{m}$ still attached structures are shown for a resolution mask exposure onto a $2.5-\mathrm{mm}$ PMMA glued substrate. The aspect ratio in this case is $\sim 25$.

The buffer layer has also improved the adhesion of structures exposed with poor contrast masks. Graphite masks [10] were replicated in 1-mm PMMA at the APS using a Pt-mirror (higher energy) and a mask with a gold absorber of $15 \mu \mathrm{m}$. For substrates prepared without the buffer layer, the adhesion loss observed can be explained by the excess dose in the adhesion layer, which results from fluorescence and secondary electron emission. This secondary emission is generated by the high- $\mathrm{Z}$ plating base absorbing high energy $x$-rays that penetrate the gold absorber. Shown in Figure 7 are 1-mm PMMA 
structures replicated using the buffer layer exposed under the same conditions of [10]. None of the features exhibit adhesion loss.

Copper is a desirable substrate for some of our devices [11] and is an example of where a high- $Z$ substrate must be used to achieve the requirements for the final part. While the buffer layer works as previously described for gold substrates, copper has another problem: this developer attacks copper, further degrading the adhesion and finish quality on the final part. However, the use of the GG developer is essential to maintaining good development contrast. Thus an additional benefit of the buffer layer is that it enables the use of "GG" developer with copper substrate/plating bases. 


\section{Conclusion}

The loss of adhesion of PMMA resists on high-Z substrates is a significant problem for DXRL using higher energy $x$-rays. The use of an optimized buffer layer consisting of spun polymer films has been shown to significantly reduce the problem. Another benefit of the buffer layer is that it enables the use of "GG" developer by protecting sensitive substrates such as copper.

\section{Acknowledgment.}

This work is supported in part by U.S. Department of Energy, BES-Materials Sciences, under contract no. W-31-109-ENG-38. 


\section{Figure Captions}

Figure 1 - "Standard" LIGA. After the exposure (a) the resist is developed (b) and used as a template for electroforming various metals (c). Finally the resist is stripped off, leaving the desired metallic structures (d).

Figure 2 - Transmitted x-ray intensity versus energy during PMMA exposures at the APS.

Figure 3 - A SEM of a 1-mm PMMA sheet prepared by gluing PMMA on a substrate using the standard process [9]

Figure 4 - "Modified" LIGA. After the exposure (a) and development of the resist (b), the buffer layer is removed by anisotropic etching using oxygen RIE (c). Thereafter, the patterned resist layer can be plated (d) and the resist stripped with solvent (e). After the stripping, additional RIE removes the remaining buffer layer ( $f$ ).

Figure 5 - Resolution mask exposed with a $0.15^{\circ} \mathrm{Cr}$ mirror, 1-mm C filter onto $1-\mathrm{mm}$ PMMA glued onto a 45-nm Au plating base substrate.

Figure 6 - Resolution mask exposed with a $0.15^{\circ} \mathrm{Pt}$ mirror, 1-mm $\mathrm{C}$ filter onto $2.5-\mathrm{mm}$ PMMA glued onto a 30-nm Au plating base substrate.

Figure 7 - Graphite masks replicated in 1-mm PMMA using the buffer layer. 


\section{References}

1 Microlithography, Micromachining and Microfabrication, Volume 2: Micromachining and Microfabrication, Ed. R. Rai-Choudhury, SPIE-IEE Press (1997), pp 299-377.

2 B. Lai, D.C. Mancini, W. Yun and E. Gluskin, "Beamline and exposure station for deep x-ray lithography at the Advanced Photon Source," SPIE Proc. 2880 (1996) p. 171.

$3 \mathrm{~J}$. Mohr, W. Ehrfeld, and D. Münchmeyer, "Requirements on resist layers in deep-etch synchrotron radiation lithography," J. Vac. Sci. B6 (6) (1988) 2264-2267.

4 D. Kadereit , J. Hormes, G. Mohn, A. El-Kholi, "Studies of the adhesion properties of LIGA microstructures by X-ray spectroscopy and mechanical measurements," Microsystem Technologies, Volume 2 Issue 2 (1996) 71-74

5 A. Schmidt, A. Clifton, W. Ehrfeld, G. Feiertag, H. Lehr, M. Schmidt, "Investigation of the adhesive strength on substrates obtained by deep X-ray lithography," Microelectronic Engineering 30 1-4 (1996) 215218.

6 F.J. Pantenburg, J. Chlebek, A. El-Kholi, H.-L. Huber, J. Mohr, H.K. Oertel, J. Schulz, "Adhesion problems in deep-etch $\mathrm{X}$-ray lithography caused by fluorescence radiation from the plating base," Microelectronic Eng. 23 (1994) 223-226.

7 J. Mohr, W. Ehrfeld, D. Münchmeyer, A. Stuz, "Resist Technology for Deep-etch Synchrotron Radiation Lithography," Makromol. Chem., Macromol. Symp. 24 (1989) 231-251

8 A. El-Kholi, J. Mohr, R. Stransky, "Ultrasonic supported development of irradiated micro-structures," Microelectronic Engineering 23 (1994) 219-222.

9 H. Guckel, T.R. Christenson, K. Skrobis; U.S. Patent 5,378,583 (1995).

10 Philip Coane, Francesco DeCarlo, Yohannes Desta, Robert Giasolli, Jost Göttert, Derrick C. Mancini, “Graphite-Based X-ray Masks for Deep and Ultra deep X-ray Lithography,” EIPBN '98 Proc. (1998).

11 J.J. Song, F. DeCarlo, Y.W. Kang, R.L. Kustom, D.C. Mancini, A. Nassiri, and B. Lai, G. Caryotakis, E.N. Jongewaard, A.D. Feinerman, V. White, "mm-Wave Cavity/Klystron Developments Using Deep X-ray Lithography at the Advanced Photon Source," submitted to the Asian Particle Accelerator Conference '98, Tsukuba, Japan, March 24-27, 1998. 

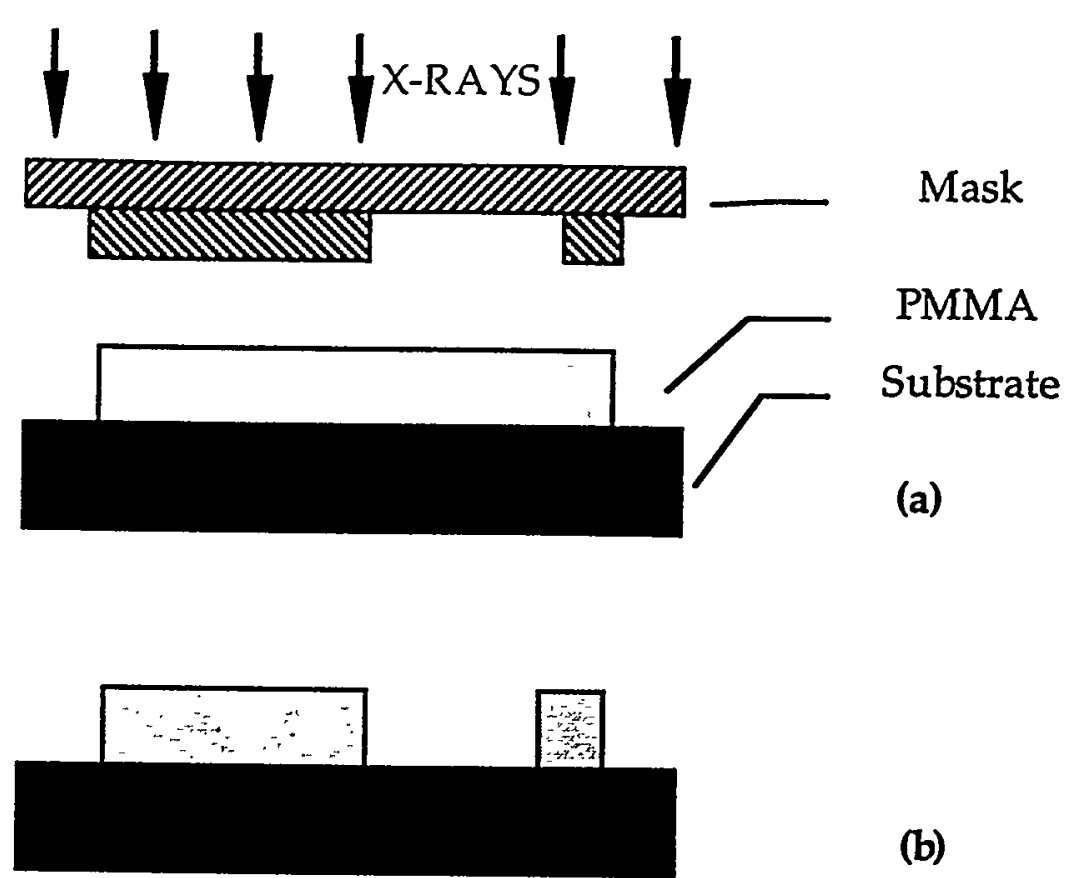

(b)

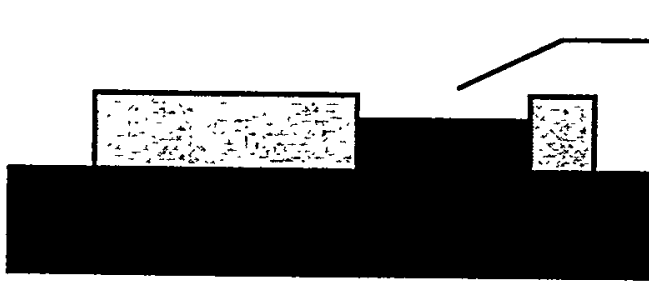

Electroplated metal

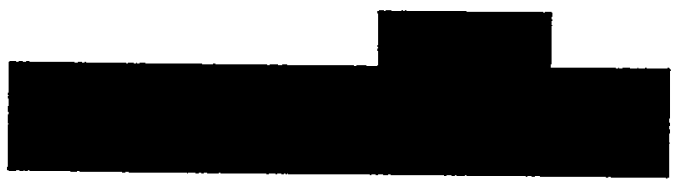

(c)

(d)

Figure 1 


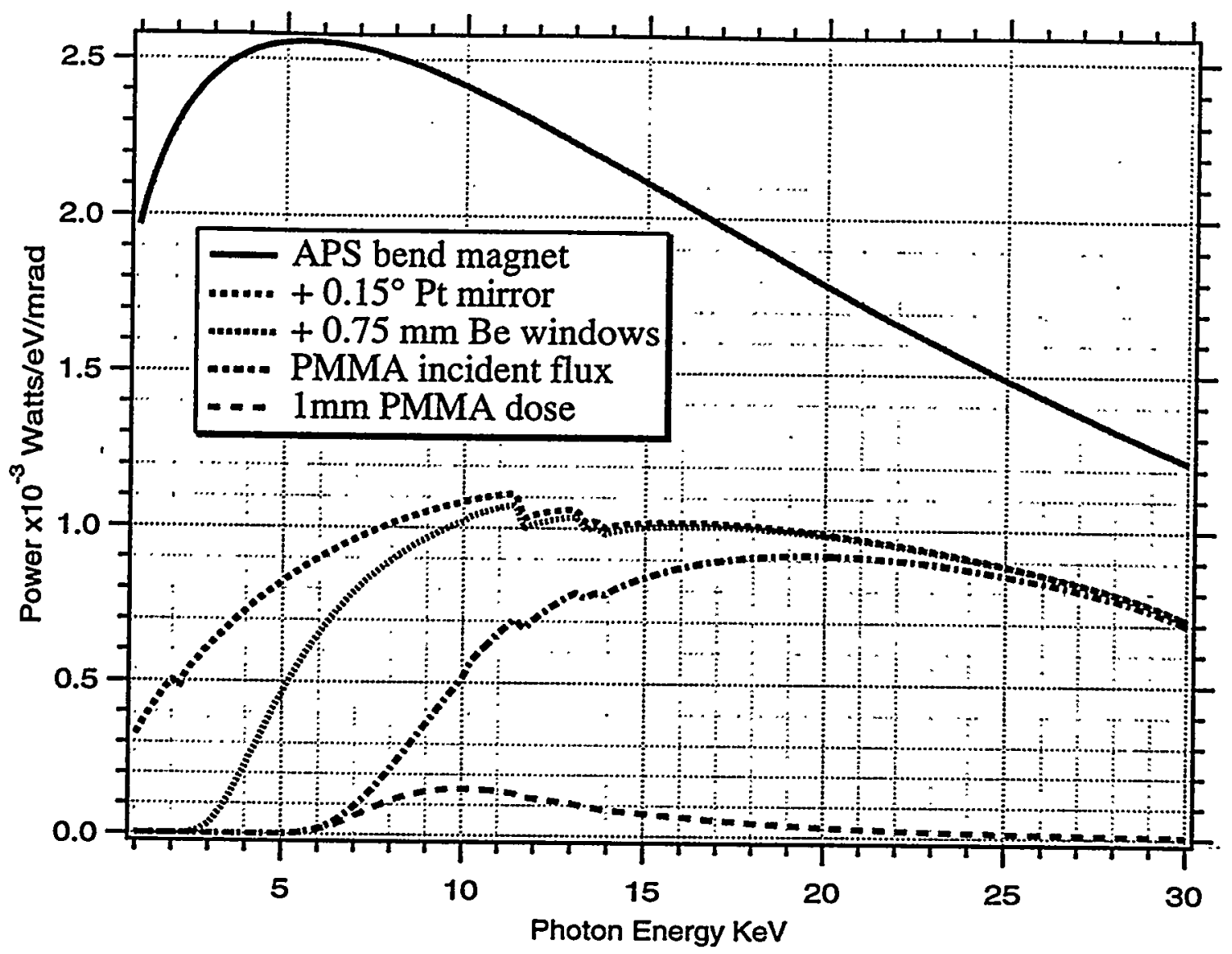

Figure 2 


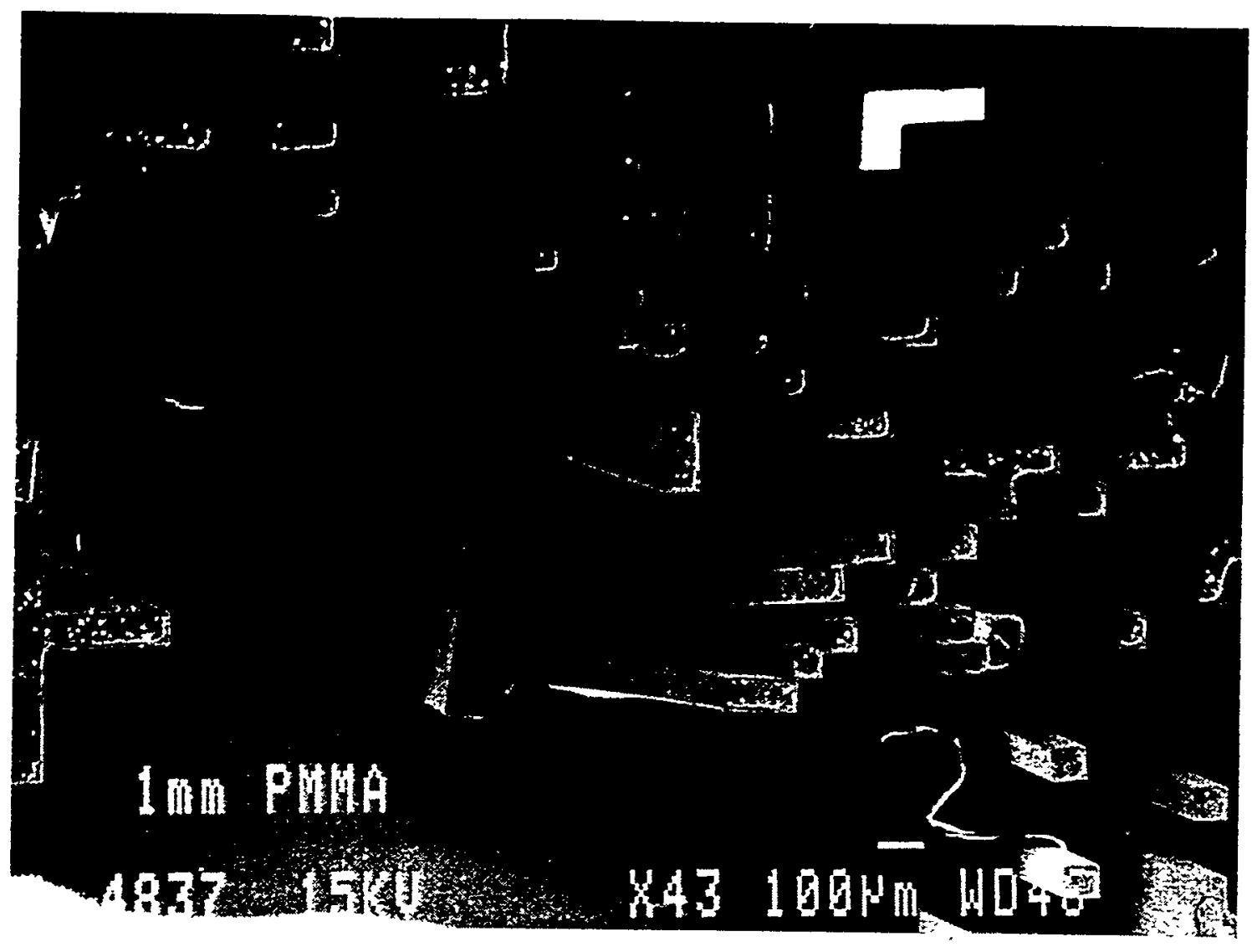

Figure 3 

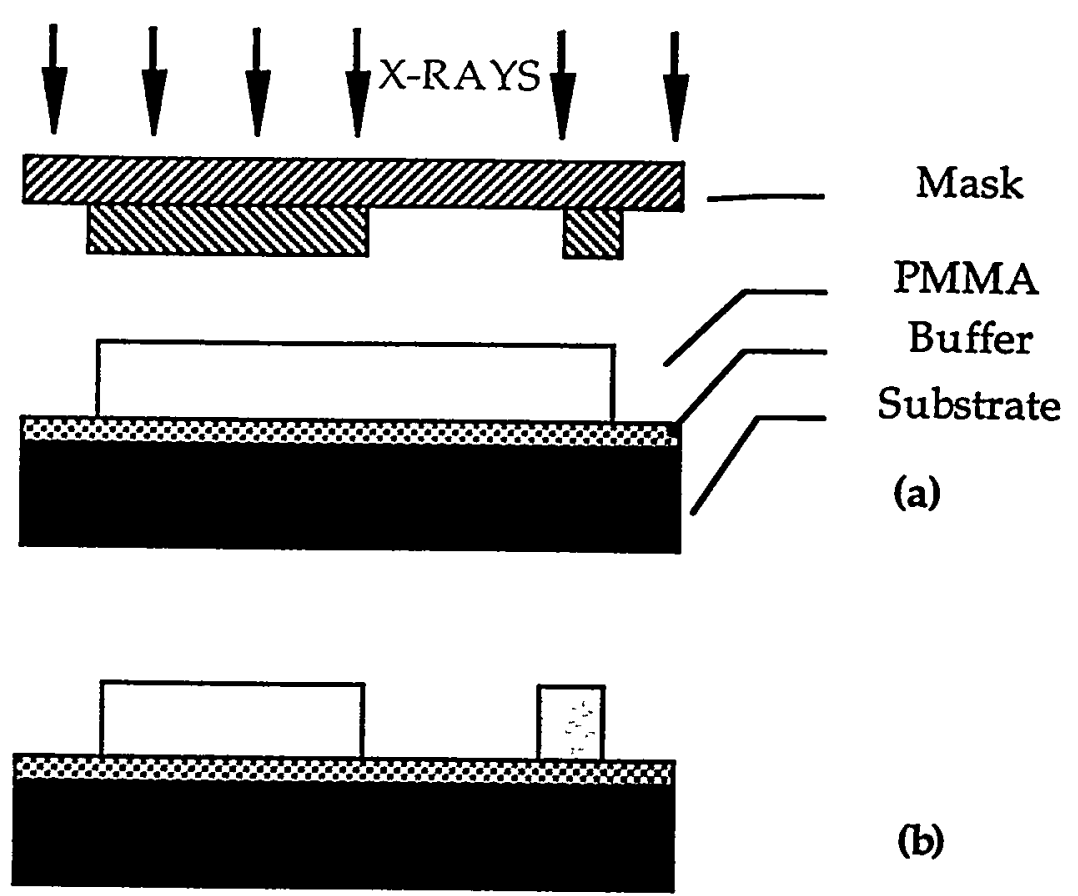

(b)
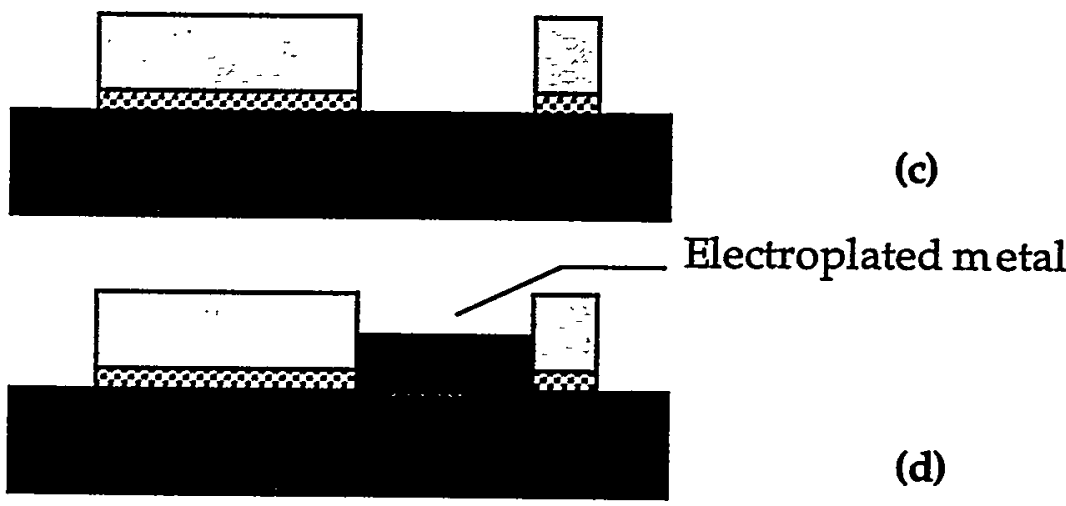

(c)

(d)

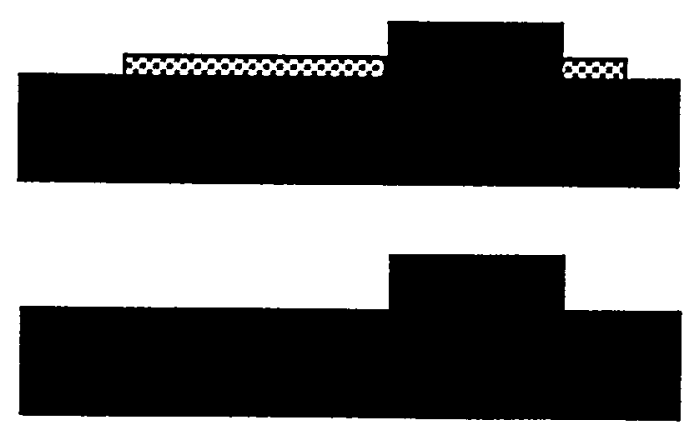

(e)

Figure 4 
8<smiles></smiles> 


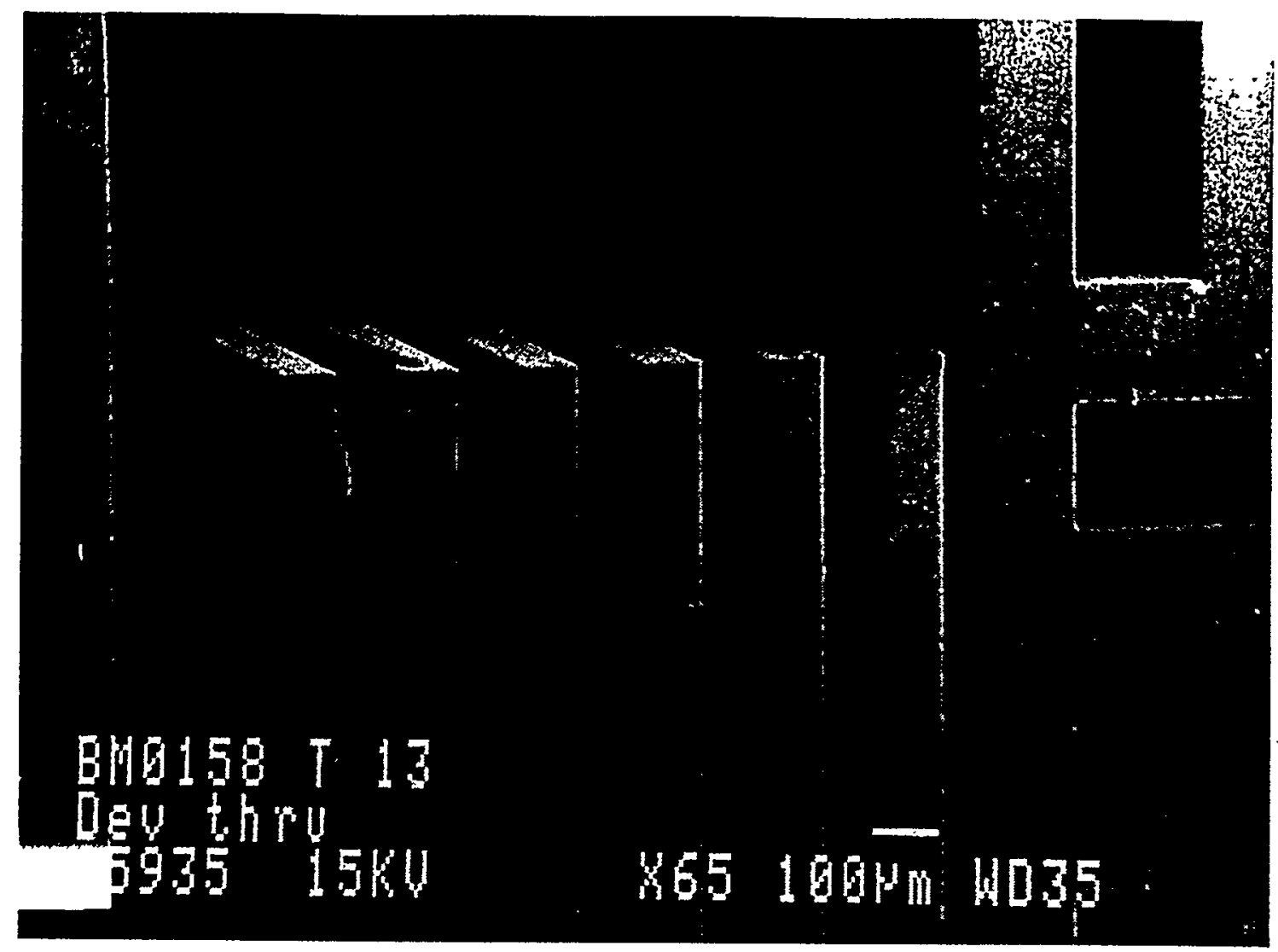

Figure 6 


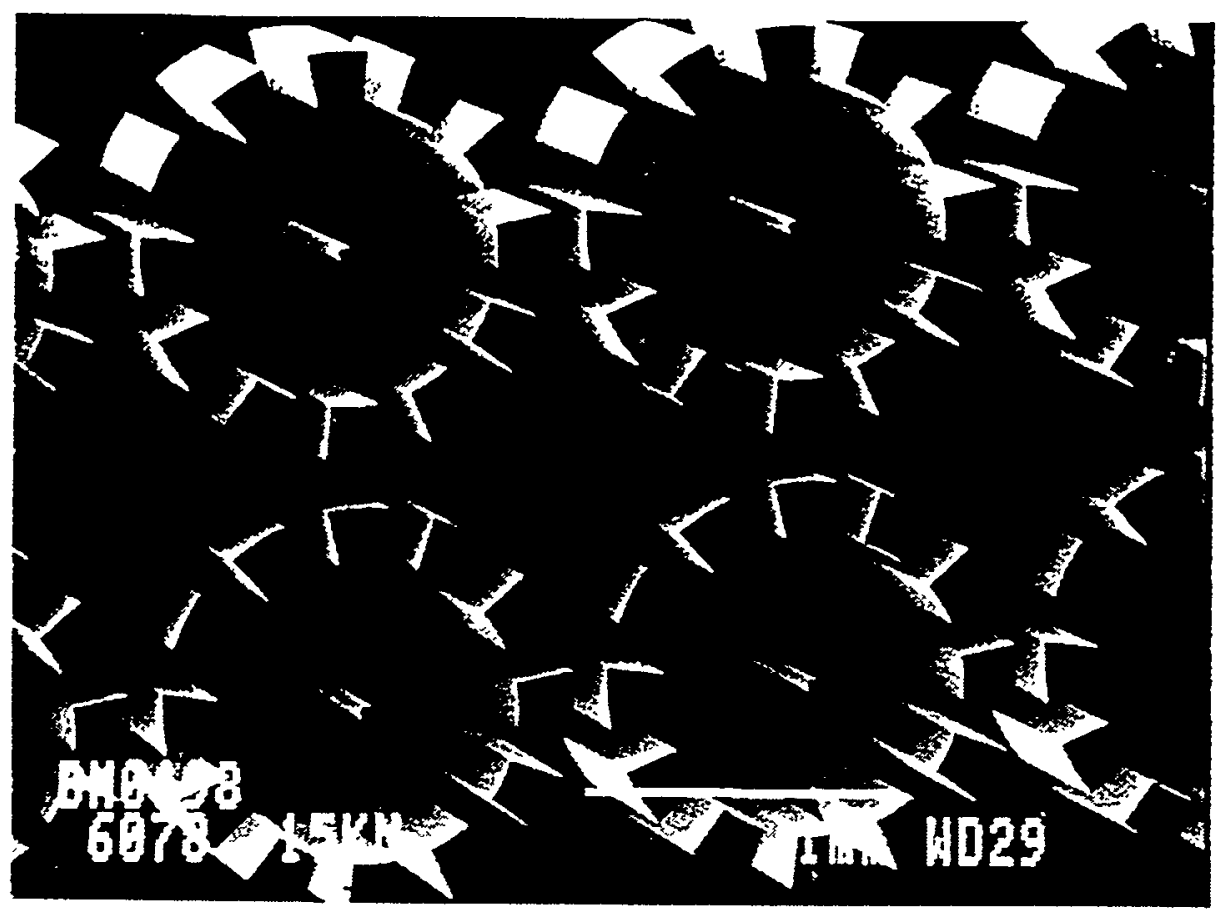

(a)

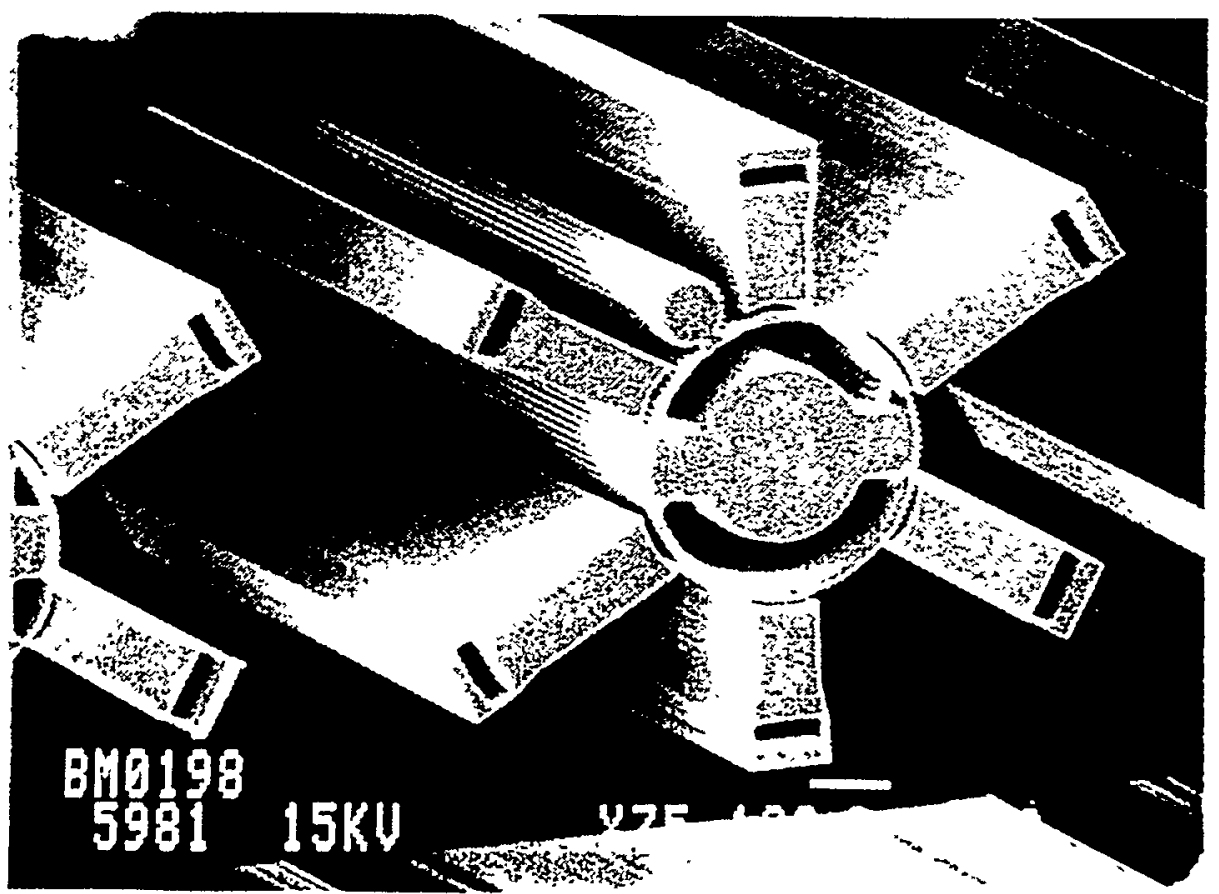




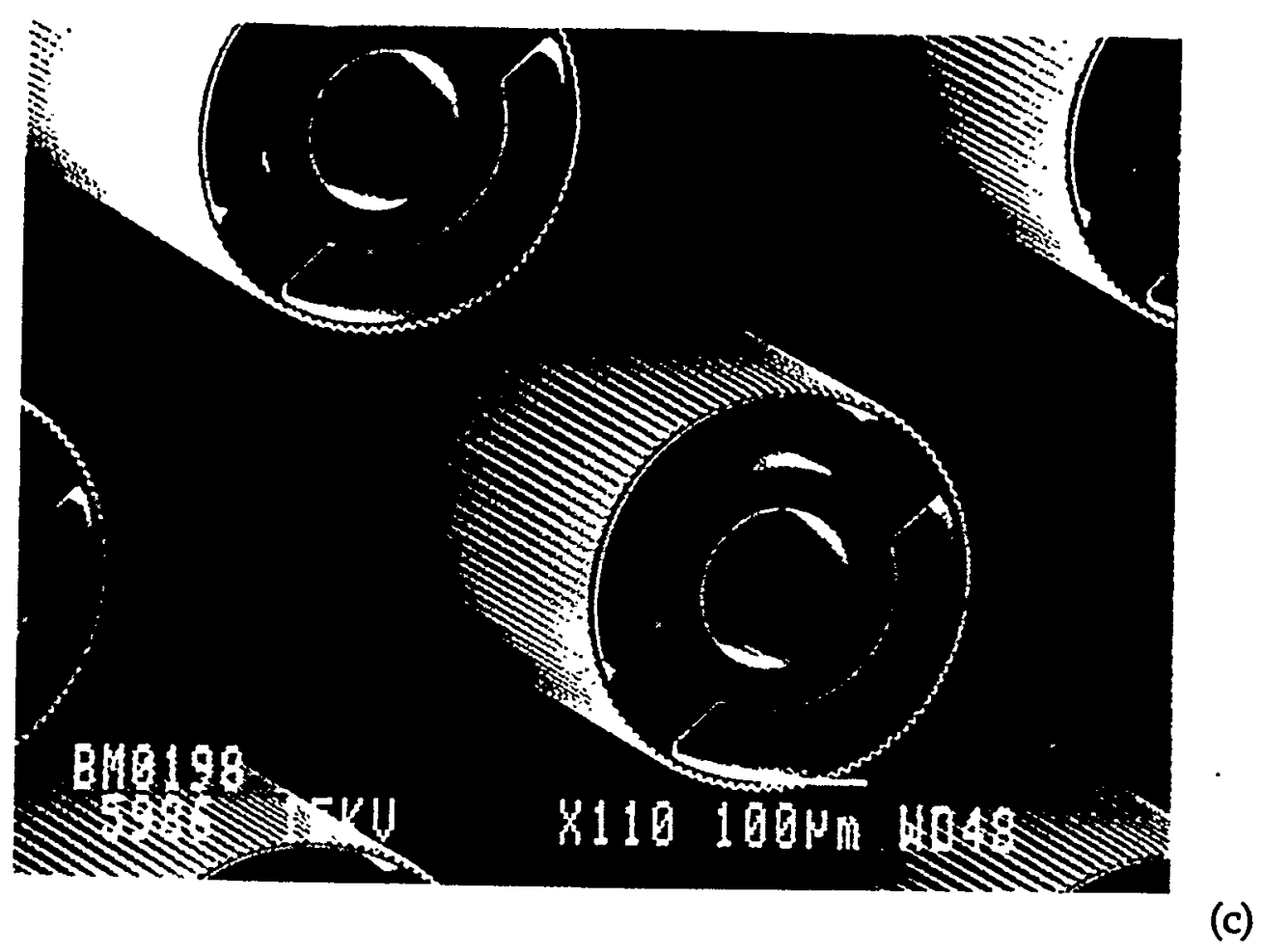

Figure 7 
4

1

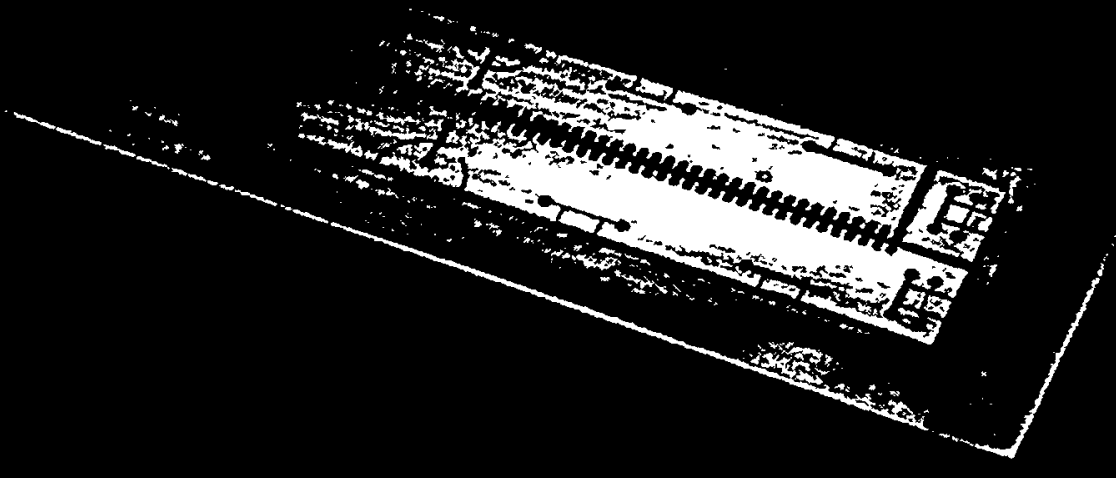

Figure 8 